\title{
Commentary: When a trial ends up in nowhere
}

\author{
Emilia Bagiella, PhD
}

In their article in this issue of the Journal, Koch and associates ${ }^{1}$ report the results of randomized clinical trial designed to determine the effect of duration of storage of red blood cells ( $\leq 14$ days vs $\geq 20$ days) transfused to patients undergoing coronary artery bypass grafting, valve surgery, or both. The trial was designed to enroll 2840 patients (1420 in each of the groups, red blood cells stored for $\leq 14$ days or $\geq 20$ days) to achieve $85 \%$ power to detect an odds ratio of 0.75 for the primary composite outcome of mortality or multisystem organ failure and cardiac, neurologic, gastrointestinal, and vascular events.

The highlight of the article of Koch and associates, ${ }^{1}$ regrettably, is not the results themselves, which were largely inconclusive, but rather the fact that the trial never reached the target sample size. During a 9- year period, the investigators were able to enroll only 1387 eligible patients, $48.8 \%$ of the anticipated sample size, and they estimated that it would take an additional 9 to 10 years to finish the target enrollment.

Koch and associates ${ }^{1}$ report several reasons for the slow enrollment and the early termination of the trial. Along with logistic factors (several of the principal investigators who were originally involved in the design and conduct of the trial, and who supported the effort, left the institution) and a decrease of financial resources, there was a reduction of the pool of eligible patients as a result of changes in transfusion and blood storage practices. Koch and associates ${ }^{1}$ concluded that the randomized trial supported neither futility nor efficacy of transfusing fresher or older red blood cells to cardiac surgical patients.

In many instances, results of clinical trials are labeled negative when the null hypothesis is not rejected. There is

\footnotetext{
From the Department of Population Health Science and Policy, Icahn School of Medicine at Mount Sinai, New York, NY.

Disclosures: Author has nothing to disclose with regard to commercial support.

Received for publication Oct 17, 2019; revisions received Oct 17, 2019; accepted for publication Oct 17, 2019; available ahead of print Oct 31, 2019.

Address for reprints: Emilia Bagiella, PhD, Department of Populations Health Science and Policy, Icahn School of Medicine at Mount Sinai, One Gustave L. Levy Place, Box 1077, New York, NY 10029 (E-mail: emilia.bagiella@ mountsinai.org).

J Thorac Cardiovasc Surg 2020;160:1517-8 $0022-5223 / \$ 36.00$

Copyright (c) 2019 Published by Elsevier Inc. on behalf of The American Association for Thoracic Surgery

https://doi.org/10.1016/j.jtcvs.2019.10.090
}

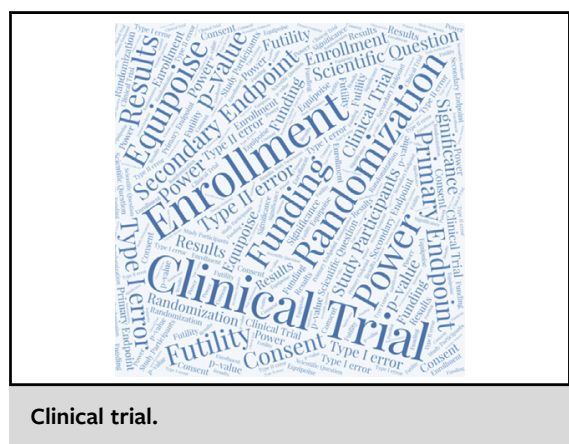

CENTRAL MESSAGE

A true negative trial is one that is unable to answer the scientific question for which it was designed.

a difference, however, in failing to reject the null hypothesis at the end of a trial that enrolled the required sample size and failing to reject the null hypothesis when less than half of the target sample size is available for analysis, as was the case in this trial. In the first instance, the trial is actually successful, whereas in the second, it is not.

Every clinical trial is (should be!) designed to answer a specific scientific question. Ultimately, the answer to that question may or may not be to the liking of the investigators. Nonetheless, it represents a legitimate ending of the scientific inquiry.

A properly designed and conducted trial that fails to reject the null hypothesis puts to rest the equipoise that justified the trial in the first place, in the exact same way that a trial that rejects the null hypothesis does. The scientific question is answered.

A very different situation presents when the trial is terminated early for lack of enrollment, which likely results in an underpowered study. This is a true negative trial, one that is unable to answer the scientific question. What can we learn from such a trial?

One important lesson is the reason why the trial did not enroll sufficient subjects. Trials fail to meet their enrollment target for a variety of reasons, including scarcity of the target population; difficulty or inability to get potential study participants to consent; lack of equipoise on the part of the investigators, the patients, or their treating physicians; shortage of financial resources; changes in clinical practice; or decreased interest in the research question. Understanding these issues does not directly help the trial that is being halted, but it does help other investigators to 
understand what circumstances led to the trial termination and how the same circumstances can be avoided in future trials.

In fact, some of these issues could be addressed before the trial even begins. For instance, sufficient resources, in terms both of funding and commitment on the part of the investigators, should be allocated and secured in advance to ensure that the trial is carried out to its end even if a change in personnel happens. In the same way, it should be seriously considered whether an investigator-initiated, singlecenter trial of several hundred patients is feasible or whether a multicenter, externally funded trial would instead be a more realistic choice.

Changes in clinical practice also affect clinical trials in many ways, all the more so the longer the trial is protracted in time. It is the responsibility of the investigators to recognize when the question the trial is designed to answer is no longer answerable or no longer relevant.
Finally, in this article, Koch and associates ${ }^{1}$ describe a novel and rather complex approach to the statistical analysis of the multiple primary end points. Although the use of the correct statistical approach is desirable in every trial, there is no statistical methodology that can rescue a trial that is terminated early for lack of enrollment. Results from such trials instead provide an invaluable lesson regarding what should be avoided in future research.

Ultimately, every trial has an unquestionable obligation to its participants: to use their time, willingness, and efforts to answer an important question. When the trial fails to do that, it has failed in its primary goal.

\section{Reference}

1. Koch CG, Sessler DI, Duncan AE, Mascha EJ, Li L, Yang D, et al. Effect of red blood cell storage duration on major postoperative complications in cardiac surgery: a randomized trial. J Thorac Cardiovasc Surg. 2020;160:1505-14.e3. 